\title{
O 'APAGÃO’ DOCENTE: LICENCIATURAS EM FOCO
}

\author{
TEACHER BURNOUT: LICENTIATE DEGREES IN FOCUS
}

\author{
EL 'APAGÓN'DOCENTE: LICENCIATURAS EN FOCO
}

\section{Rosimar Serena Siqueira Esquinsani ${ }^{1}$ \\ Valdocir Antonio Esquinsani ${ }^{2}$}

${ }^{1}$ Doutora em Educação pela UNISINOS. Docente do Programa de Pós-Graduação em Educação da Universidade de Passo Fundo (UPF), Passo Fundo, RS, Brasil.

${ }^{2}$ Mestre em Letras pela PUC/RS. Docente do Instituto de Filosofia e Ciências Humanas, da Universidade de Passo Fundo (UPF), Passo Fundo, RS Brasil.

Resumo: Avizinha-se o risco de 'apagão' docente na Educação Básica brasileira. Tal risco assentase, sobretudo, em duas constatações: a parca opção por cursos de licenciatura e a defasagem quantitativa entre o número de jovens professores e o número de docentes na etapa final de suas carreiras. Para fazer o enfrentamento desta situação, são necessárias soluções estruturais que passariam por dois movimentos: a) o investimento na atratividade e a permanência na carreira docente, e b) o fortalecimento dos cursos de licenciatura. Na esteira desse debate, o artigo objetiva discutir circunstancialmente o ensino nos cursos de licenciatura e a sua potencial contribuição para a superação do deficit crescente de professores. Para essa discussão, o artigo foi pautado em base bibliográfica, conduzida por metodologia analítico-reconstrutiva, edificada a partir da análise de conteúdo sobre dois procedimentos de coleta de informações: dados de contexto e utilização de grupo focal. Como conclusão, o texto confirma as licenciaturas como apoio para a solução estrutural do 'apagão' docente. Já no que concerne ao debate específico sobre o ensino nos cursos de licenciatura, há duas perspectivas: a) a necessidade de cursos específicos para a formação docente - visto que a atividade docente não pode ser descolada de uma preparação específica; e b) a convivência curricular de dois grandes núcleos: os conhecimentos disciplinares e os conhecimentos pedagógicos ou didáticos, ambos tomados como elementos centrais na formação de professores.

Palavras-chave: 'Apagão' docente; Licenciatura; Formação docente inicial.

Abstract: The risk of teacher burnout in Brazilian basic education is increasing. This risk is based, in particular, on two findings: the lack of choice for undergraduate courses, and the quantitative gap between the number of young teachers and the number of teachers in the final stage of their careers. In order to mitigate with this situation, structural solutions are needed that would include two movements: a) investments in attracting encouraging teachers to remain in the career, and b) strengthening the licentiate degree. In light of this debate, the article offers a circumstantial discussion on teaching in undergraduate courses, and its potential contribution to overcoming the growing lack of teachers. This article was based on bibliographic research, conducted using an analytical-reconstructive methodology, based on the analysis of content derived from two information collection procedures: context data and a focal group. In conclusion, the text confirms the licentiate degree as support for the structural solution of teacher burnout. Regarding the specific debate on teaching in undergraduate courses, there are two perspectives: a) the need for specific courses for teacher education, as the teaching activity can not be detached from a specific training, 
and b) the curricular coexistence of two major groups: disciplinary knowledge and pedagogical or didactic knowledge, both of which are seen as central elements in teacher training.

Key words: Teacher burnout; Licentiate degree; Initial teacher training.

Resumen: Se avizora el riesgo de 'apagón' docente en la educación básica brasileña. Este riesgo se basa, principalmente, en dos constataciones: la parca opción por cursos de licenciatura y el desfase cuantitativo entre el número de jóvenes profesores y el número de docentes en la etapa final de sus carreras. Para hacer el enfrentamiento a la situación, son necesarias soluciones estructurales que pasarían por dos movimientos: a) la inversión en el atractivo y permanencia en la carrera docente, y b) el fortalecimiento de los cursos de licenciatura. En el marco de este debate, el artículo objetiva discutir circunstancialmente la enseñanza en los cursos de licenciatura y su potencial contribución a la superación del déficit creciente de profesores. Para esta discusión, el artículo fue pautado en base bibliográfica, conducida por metodología analítico-reconstructiva, edificada a partir del análisis de contenido sobre dos procedimientos de recolección de informaciones: datos de contexto y la utilización de grupo focal. Como conclusión, el texto confirma las licenciaturas como apoyo a la solución estructural del apagón docente. En lo que concierne al debate específico sobre la enseñanza en los cursos de licenciatura, hay dos perspectivas: a) la necesidad de cursos específicos para la formación docente - puesto que la actividad docente no puede ser descolgada de una preparación específica y, b) la convivencia curricular de dos grandes núcleos: los conocimientos disciplinares y los conocimientos pedagógicos o didácticos, ambos tomados como elementos centrales en la formación de profesores.

Palabras clave: 'Apagón' docente; Licenciatura; Formación docente inicial.

\section{O 'APAGÃO' DOCENTE: LICENCIATURAS EM FOCO}

O termo 'apagão' (FRIGOTTO, 2007) docente, 'apagão' de professores, 'apagão pedagógico' ou ainda 'apagão' na educação, tem sido utilizado por parte da mídia para designar a iminente falta de professores para atendimento da demanda por escolarização básica em um futuro próximo. Há pelo menos dez anos (BRASIL, 2007) o eventual deficit docente tem sido indicado como uma possibilidade concreta. Essa falta de professores é prognosticada a partir do cotejo de indicadores de acesso, permanência e titulação nos cursos de licenciatura, associados à baixa atratividade material da profissão, ao consequente esvaziamento da busca jovem pela carreira docente e ao crescente contingente de professores nas etapas finais da carreira.

Na esteira dessa possibilidade, o artigo objetiva discutir circunstancialmente o ensino nos cursos de licenciatura como espaço de formação docente inicial e suas potenciais contribuições para fazer o enfrentamento ao deficit crescente de professores e ao possível apagão que se avizinha.

Para cumprir seu objetivo, a pesquisa que deu origem ao texto em tela foi realizada em base bibliográfica prioritariamente (revisão de literatura), apoiando-se subsidiariamente em dados de contexto; na citação de algumas legislações como parte da composição do cenário conjuntural e nos dados advindos de grupo focal articulado em torno do tema 'formação nas licenciaturas'.

Os dados de contexto foram utilizados para ilustrar o fenômeno do 'apagão' que se aproxima. Já os grupos focais, configurados com egressos de cursos de licenciatura, foram utilizados como produtores de dados ilustrativos para o enredo e reflexões exaradas no âmbito do texto, mormente 
no que concerne às licenciaturas como espaço de formação de futuros professores, bem como nas questões que esta formação pode favorecer em face ao 'apagão' docente previsto.

A pesquisa foi pautada, ainda, por uma metodologia analítico-reconstrutiva, apresentando potenciais subsídios ao debate sobre o 'apagão' docente e as licenciaturas a partir dos recursos advindos da pesquisa científica. Os textos foram examinados a partir do procedimento da análise de conteúdo, utilizando-se a técnica da análise temática, para sistematização dos dados advindos dos grupos focais, cujo "[...] tema é a unidade de significação que se liberta naturalmente de um texto analisado, segundo critérios relativos à teoria que serve de guia à leitura" (BARDIN, 2007, p.105).

\section{O 'APAGÃO' DOCENTE}

No contexto do ensino superior brasileiro em 2016, as matrículas nos cursos de licenciatura representavam 18,9\% do total. Ainda em 2016 o Brasil contabilizou 7.356 cursos superiores de licenciaturas, com cerca de 1,5 milhão de estudantes matriculados e 238.919 alunos concluintes, de acordo com os dados do Censo da Educação Superior, sistematizados pelo Instituto Nacional de Estudos e Pesquisas Educacionais Anísio Teixeira (INEP) e publicizados por meio de "Notas Estatísticas" (BRASIL, 2017). É lícito inferir, pelo conjunto de dados apresentados, que há uma tímida matrícula em cursos de licenciatura, assim como é tímido também o percentual de concluintes em razão do total de matrículas na casa dos $15 \%$.

Na esteira dos dados de matrícula nas licenciaturas - tímidos e acanhoados -, somamse outros dados que indicam a dimensão de urgência do possível 'apagão' docente. Para ilustrar as possibilidades concretas desse apagão, é espantosa a diferença entre o número de jovens professores em início de carreira, quando comparado ao número de docentes mais experientes, com cinquenta anos ou mais, que estão se dirigindo para o final de suas carreiras.

Quando se examina a série histórica - estabelecida entre os anos de 2007 a 2017 referente ao número de docentes na Educação Básica brasileira, a diferença entre o número de jovens professores ingressantes e o número de professores que estão mais próximos ao final da carreira chega, em 2017, a proporção a 4 por 1.

Tabela 01 - Docentes na Educação Básica

\begin{tabular}{|l|l|l|l|}
\hline ANO & TOTAL & Até 24 anos & $\mathbf{5 0}$ anos ou mais \\
\hline $\mathbf{2 0 0 7}$ & 1.882 .861 & 114.364 & 223.388 \\
\hline $\mathbf{2 0 0 8}$ & 1.988 .161 & 117.015 & 242.767 \\
\hline $\mathbf{2 0 0 9}$ & 1.977 .978 & 116.523 & 251.011 \\
\hline $\mathbf{2 0 1 0}$ & 1.999 .518 & 109.542 & 306.694 \\
\hline $\mathbf{2 0 1 1}$ & 2.039 .261 & 104.758 & 328.141 \\
\hline $\mathbf{2 0 1 2}$ & 2.095 .013 & 104.579 & 344.439 \\
\hline $\mathbf{2 0 1 3}$ & 2.141 .676 & 105.496 & 370.025 \\
\hline $\mathbf{2 0 1 4}$ & 2.184 .267 & 109.484 & 366.327 \\
\hline $\mathbf{2 0 1 5}$ & 2.187 .154 & 106.485 & 390.736 \\
\hline $\mathbf{2 0 1 6}$ & 2.196 .397 & 97.554 & 414.453 \\
\hline $\mathbf{2 0 1 7}$ & 2.192 .224 & 91.240 & 433.620 \\
\hline
\end{tabular}

Fonte: Organização dos autores com base nas Sinopses Estatísticas da Educação Básica de 2010 a 2017; bem como nas Sinopses Estatísticas do Professor de 2007 a 2009. As sinopses de 2005 e 2006 não apresentam dados sobre a faixa etária dos professores. 
O gráfico a seguir dá uma dimensão visual dessa diferença.

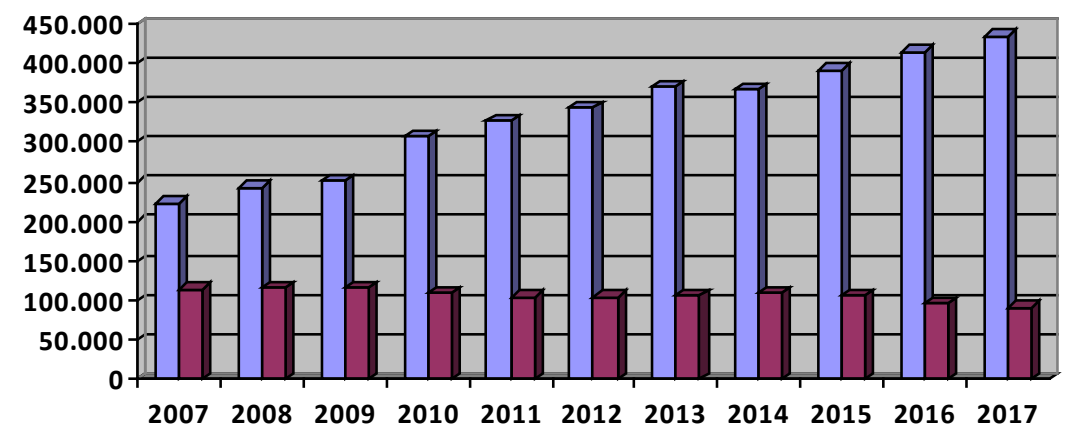

$\square$ Professores com 50 anos ou mais
$\square$ Professores com até 24 anos

Fonte: Organização dos autores, com base nas Sinopses Estatísticas da Educação Básica de 2010 a 2017; bem como nas Sinopses Estatísticas do Professor de 2007 a 2009. As Sinopses de 2005 e 2006 não apresentam dados sobre a faixa etária dos professores.

A defasagem proporcional entre uma faixa etária e outra, que no início da série história, em 2007, é de 1,95 professores possivelmente em final de carreira, em relação proporcional a cada um professor ingressante, aumenta gradativa e substancialmente até o final do período em recorte chegando, em 2017, à proporção de 4,76 professores em etapas finais de carreira, em relação a um jovem professor ingressante.

A situação parece alarmante, visto que há o predomínio ascendente de um grande número de docentes com 50 anos ou mais, possivelmente encaminhando-se para o final da carreira em relação ao número de professores com até 24 anos e, possivelmente, em início de carreira.

Os 25 anos de vida produtiva que separa um grupo etário de outro tende a repercutir em um considerável hiato de docentes ao longo de um período próximo, que provavelmente será asseverado, se se considerar o tímido número de jovens que procuram as licenciaturas para suas formações iniciais. Diante dos dados publicizados, fica difícil negar a necessidade de uma discussão circunstanciada sobre o tema do deficit docente, assim como se torna problemático e leviano o apelo a qualquer situação artificial e externa à própria classe e demandas da docência, como eventuais aumentos da faixa etária para a consecução da aposentadoria, por exemplo.

Está-se, assim, consciente de que "o Brasil possui cerca de cinco milhões de professores, dois milhões destes atuando na Educação Básica. Se a profissão não se renovar, tendo em vista o número de aposentadorias maior que o de formandos, quem educará as novas gerações?" (CERICATO, 2016, p. 284)

Para o enfrentamento de tal fenômeno se tem, contemporaneamente, o desenho de algumas políticas. Entretanto, essas políticas dão conta de soluções emergenciais, como o apelo à terceirização e aos contratos emergenciais ou temporários, respaldados pela Lei 13.429, de 31 de março de 2017, que dispõe sobre o trabalho temporário e as relações de trabalho na empresa de prestação de serviços a terceiros. $O \S 3^{\circ}$ do Art. $9^{\circ}$ da referida lei traz uma prescrição jurídica que adiciona aos contratos temporários um ingrediente que os 
estende e legitima no que concerne à educação: o contrato temporário pode versar sobre atividades-fim, no caso, a docência.

Outra solução emergencial talvez recaia (e aqui se trata de uma mera possibilidade, pois não há nenhum indicativo legal explícito acerca do assunto) sobre a utilização de profissionais com 'notório saber', ainda que a lei não mencione sua utilização em substituição a professores de carreira ou de todas as áreas, visto que os profissionais com notório saber, na estrita interpretação na lei, atuarão "exclusivamente para atender ao inciso V do caput do art. 36" (Inciso IV do Art. 61 da Lei 9.394/1996, incluído pela Lei n 13.415, de 2017), ou seja, exclusivamente para atender a formação técnica e profissional no âmbito do Ensino Médio.

Todavia, compreende-se que há movimentos/soluções que podem alterar a situação do deficit de professores para atendimento à Educação Básica no Brasil de maneira estrutural e determinante, sobretudo o investimento na materialidade da carreira docente, que passa por condições de trabalho, planos de cargos e salários, mas também pelo necessário investimento na formação inicial, colocando as licenciaturas como pautas que corroboram para a solução estrutural ao 'apagão' docente.

\title{
As liCENCIATURAS FRENTE AO 'APAGÃo' DOCENTE: PAUTA NECESSÁRIA
}

O risco crescente do 'apagão' docente implica que o tema da docência no Brasil seja tratado a partir de alguns pontos nevrálgicos. Um desses pontos, seguramente, é o que tenciona a situação material da docência. Há quase vinte anos, Gatti já alertava que o magistério convivia com "salários aviltantes, desvalorização profissional, imagem social ambígua dos professores, baixa autoestima e descontinuidade de políticas são fatores de perturbação e desarticulação nos sistemas de ensino, sem nenhuma dúvida" (GATTI, 1991, p.64). Parece que a situação pouco mudou, favorecendo o 'apagão' que se avizinha. Diante desse cenário, é forçoso sopesar movimentos que tornem a carreira docente atrativa para os jovens.

Do ponto de vista material, tornar a carreira docente atrativa para os iniciantes implica o atendimento de alguns requisitos:

\begin{abstract}
1. Remuneração proporcional à formação com equiparação às demais profissões com formação equivalente [...] 2. Ascensão na carreira de acordo com o tempo de serviço e a titulação/ formação [...] 3. Alcance do topo da carreira como uma possibilidade para todos e não restrito à minoria [...] 4. Progressão horizontal com interstícios não muito longos [...] 5. Valorização do professor de acordo com a sua titulação/formação, desde o início da carreira [...] 6. Dispersão salarial ao longo da carreira que garanta a atratividade para a permanência na profissão [...] 7. Consideração do custo de vida regional (MASSON, 2017, p. 857-860)
\end{abstract}

Entretanto, o investimento na atratividade e na permanência na carreira docente vai além da necessária pauta material, sugerindo também a problematização de outros pontos, entre eles o debate circunstanciado e o consequente aperfeiçoamento dos processos de formação docente inicial desenvolvidos nos cursos de licenciatura.

A presença relativamente recente das licenciaturas como espaço da formação de professores no Brasil - que remete à criação das primeiras Faculdades de Filosofia, Ciências e Letras, na década de 1930 -, associada a pouca atratividade material que envolve, hoje, a grande 
maioria das carreiras docentes na Educação Básica; ao panorama da oferta e procura de vagas nestes cursos; aos debates sobre os processos formativos inerentes aos cursos superiores, entre outras situações contextuais, tem tornado o ensino nas licenciaturas uma discussão cogente.

Além do mais, os recentes movimentos de políticas educacionais que incluem - mas não apenas - as leis no 13.174/2015 e n 13.415/2017; a Portaria Capes n 38, de 28 de fevereiro de 2018; o Edital Capes n 6/2018 - Residência Pedagógica, bem como o Edital Capes n 7/2018 - Programa Institucional de Bolsa de Iniciação à Docência (Pibid), tem instado às instituições que mantêm licenciaturas a uma discussão mais densa sobre tais cursos.

\footnotetext{
A formação inicial [...] parece-nos eixo central nesse processo para que seja atendida a necessidade atual da escola e do seu dia a dia, para tanto um primeiro passo consiste em repensar seu modo de configuração. Com o perfil de estudantes que procuram a docência - provenientes de classes menos privilegiadas -, há que se pensar em uma formação sólida, presencial, integral e subsidiada pelo Estado, porque se lhe cabe educar a população, cabe-lhe também formar seus professores (CERICATO, 2016, p. 285)
}

Assim, tornar a carreira docente atrativa implica, entre outros movimentos, aprofundar o debate sobre o ensino nos cursos de licenciatura, de modo a garantir organicidade e sentido formativo, além de apresentar, ao futuro professor, um panorama aproximado dos desafios da docência e dos instrumentos teóricos e práticos por meio dos quais tais desafios podem ser enfrentados.

Para a discussão sobre a formação necessária nos cursos de licenciatura, utilizou-se o procedimento técnico de produção de dados a partir de grupos focais (BOMFIM, 2009). Grupo Focal tem como objetivo:

[...] reunir informações detalhadas sobre um tópico específico (sugerido pelo pesquisador, coordenador ou moderador do grupo) a partir de um grupo de participantes selecionados. Ele busca colher informações que possam proporcionar a compreensão de percepções, crenças, atitudes sobre um tema, produto ou serviço (BOMFIM, 2009, p. 780)

Os grupos focais foram constituídos por 20 egressos de cursos de licenciatura de uma universidade comunitária do norte do estado do Rio Grande do Sul, divididos em dois grupos de 10 sujeitos, tendo como objetivo garantir a fala e a manifestação de opiniões por cada um dos sujeitos convidados. Os grupos se estabeleceram voluntariamente, a partir de um convite direcionado a alunos de um Programa de Pós-Graduação desenvolvido na instituição em tela. Foram compostos por 06 egressos do curso de Pedagogia; 03 egressos do curso de Filosofia; 03 egressos do curso de História; 02 egressos do curso de Educação Física; 02 egressos do curso de Biologia; 02 egressos do curso de Matemática; 01 egresso do curso de Física e 01 egresso do curso de Geografia.

Partindo da premissa que o Grupo Focal "difere da entrevista individual por basearse na interação entre as pessoas para obter os dados necessários à pesquisa [...]" (BOMFIM, 2009, p. 780), cada um desses egressos foi instado a interagir com os demais membros do grupo, em um debate franco, sobre a formação que receberam nos seus respectivos cursos de licenciatura, como esta formação auxilia no fortalecimento da profissão docente e quais as demandas da formação para o professor da Educação Básica.

Os grupos focais levantaram pautas pertinentes em relação ao assunto, sendo particularmente relevante a centralidade que os membros dos grupos atribuíram ao tema 'currículo' como espaços de construção/solidificação da identidade do futuro professor. 
A relevância de cursos específicos para a formação de professores parte da compreensão de que a atividade docente não pode ser descolada de uma preparação característica, visto que tal preparação estaria diretamente relacionada com a qualidade da educação. Assim, há a evidência das licenciaturas como espaço primordial para a formação docente inicial, em uma relação direta com a qualidade da educação. Em razão dessa relação, Nóvoa aduz que:

[...] não há ensino de qualidade, nem reforma educativa, nem inovação pedagógica, sem uma adequada formação de professores. Esta afirmação é de uma banalidade a toda prova. E, no enquanto, vale a pena recordá-la num momento em que o ensino e os professores se encontram sob fogo cruzado das mais diversas críticas e acusações (NÓVOA, 1992, p. 17).

Muitas falas advindas dos grupos focais referendaram essa perspectiva: ficou patente a compreensão de que os aprendizados no âmbito dos cursos de licenciatura foram definidores da identidade profissional, sendo diverso de outros aprendizados em cursos cuja docência não tem papel central.

Desta constatação resultou que, no debate dos grupos, o currículo assumiu papel protagonista, assim como o tracejo de normas comuns para a formação docente, cogente "para o projeto nacional da educação brasileira, em seus níveis e suas modalidades da Educação Básica, tendo em vista a abrangência e a complexidade da educação de modo geral e, em especial, a educação escolar inscrita na sociedade" (BRASIL, 2015, p. 21). De modo geral, a articulação de currículos com um projeto nacional (para onde vamos?) bem como a complexidade e o caráter multifacetado do currículo manifestaram-se também como preocupações dos membros dos grupos.

Em geral, o currículo é uma 'arena de disputas' no interior das Instituições de Ensino Superior, posto que estão envolvidas em uma discussão curricular questões cotidianas como definições de carga horária; divisões de turmas; organização de horários, etc. Tais questões não são apenas mecanismos de gestão das instituições, mas também estratégias de poder em torno de sujeitos, disciplinas e, em última instância, de definição de currículos.

O currículo é, igualmente, "um campo de políticas culturais, terreno de acordos e conflitos em torno da legitimação ou não de diferentes saberes, capaz de contribuir na formação de identidades individuais e sociais" (LOPES, 1999, p. 18), sendo o resultado dessas disputas a materialidade do currículo e, por conseguinte, a característica identitária do egresso. Assim um currículo diz mais sobre os entendimentos e as forças dos sujeitos que participam de sua elaboração, do que necessariamente sobre as melhores escolhas pedagógicas.

Tal situação ficou evidente em falas coletadas junto aos grupos focais, visto que $80 \%$ dos 20 partícipes (ou 16 sujeitos) explicitaram que, em suas licenciaturas, a correlação de forças que conduzia o currículo era bastante evidente, sobretudo com o predomínio de determinadas áreas disciplinares sobre outras, em especial, aquelas áreas indexadas a docentes com mais 'força' junto ao curso (essa 'força' seria medida, de acordo com os sujeitos partícipes da pesquisa, de diferentes formas: por serem os professores mais antigos, ou vinculados a Programas de Pós-Graduação, ou ainda por estarem em cargos de destaque acadêmico).

Outro ponto de relevo nos grupos focais incidiu sobre o desconhecimento - quase generalizado - da totalidade dos currículos que foram desenvolvidos na trajetória formativa dos 
sujeitos da pesquisa. Muitos egressos relataram desconhecer ou não ter sido tempestivamente apresentados ao conjunto das disciplinas e dos objetivos instrucionais das mesmas, bem como sua posição e pertinência no curso. Assim, parece lícito supor que a formação inicial de professores requer um projeto que supere o modelo de "currículos ainda fragmentados, demasiadamente especializados e abreviados" (TARDIF, 2013, p. 283).

Ainda atendendo à pauta dos currículos, alguns temas não deveriam ficar 'de fora' da formação de professores, particularmente as matérias da área de fundamentos pedagógicos ou disciplinas didático-metodológicas. Disto resulta a convivência curricular de dois grandes núcleos: os conhecimentos disciplinares e os conhecimentos pedagógicos ou didáticos, ambos tomados como elementos centrais na formação de professores.

Nessa direção, "a formação de professores [...] precisa estabelecer relações teóricas e práticas mais sólidas entre a didática e a epistemologia das ciências, de modo a romper com a separação entre conhecimentos disciplinares e conhecimentos pedagógico-didáticos" (LIBÂNEO, 2012, p. 16) ou, de outra maneira, romper com a hierarquização interna nos cursos de licenciatura, cujas disciplinas pedagógico-didáticas restam por ocupar um espaço periférico e, por vezes, diminuto.

Tal afirmação é corroborada pelos grupos focais. Dos partícipes da pesquisa, 17 sujeitos evidenciaram que, em algumas licenciaturas, as disciplinas pedagógico-didáticas eram minimizadas, por vezes até na forma de discursos pronunciados por professores das disciplinas de conhecimentos específicos. O descolamento da formação do licenciado em razão da formação do profissional 'liberal' (detentor prioritário de conhecimentos específicos), foi sublinhada em alguns cursos, reverberando no descaso de alguns egressos para com as disciplinas 'da pedagogia'.

Houve, exemplarmente, o relato de uma egressa de uma licenciatura da área das ciências exatas, que contou a seguinte situação: "em certa ocasião uma colega recebeu o retorno da avaliação de uma disciplina 'da pedagogia'. Ela havia tirado nota máxima, mas ao receber a prova, lastimou receber nota máxima 'nesse tipo de disciplina'".

Esta preferência pela formação técnica baseada prioritariamente em conhecimentos disciplinares resta por obstaculizar a formação do licenciado, colocando-o em uma falsa expectativa profissional que o distancia da docência. O licenciando está matriculado em um curso de licenciatura, mas não quer ser professor ou não reconhece a licenciatura como espaço de formação do professor.

Sobre este ponto, um relato interessante foi realizado por parte de um egresso de um curso da área das ciências da saúde, que relatou uma enquete informal que foi realizada em sua turma de graduação. $O$ professor de uma determinada disciplina pedagógicodidática perguntou quem, dentre os 48 alunos matriculados, seria professor. Só uma menina levantou a mão...

A reflexão curricular necessária parte da compreensão de que é indispensável para a formação inicial de professores (sobretudo a formação de professores em outros cursos que não o de pedagogia)... 
Superar o modelo em que disciplinas de educação se agregam ao currículo dos bacharelados na expectativa que essa formação seja suficiente para o professor exercer seu trabalho se mostra fundamental. Formar professores é diferente de formar especialistas disciplinares, mas lidar com essa questão não é fácil porque requer uma mudança de mentalidades [...] Não se trata de desprezar os conhecimentos específicos, mas de escolher, em cada área, o que é importante que um professor saiba. (CERICATO, 2016, p. 286)

Associados a esses dois grandes núcleos, igualmente parece adequado ter como horizonte três pontos que dialogam intrinsecamente e que apareceram, de maneira forte, nas falas presentes nos grupos focais: a) o espaço da pesquisa em educação; b) o cotidiano de atuação docente como dimensão formativa por excelência; e c) as tendências mais amplas das políticas educacionais.

O primeiro ponto - o espaço da pesquisa em educação nas elaborações e nas decisões curriculares que implicam a formação de futuros docentes - aparentemente carece de reforços a partir de dois movimentos:

\begin{abstract}
[...] o primeiro movimento parte da afirmação da necessidade de aproximar as pesquisas em educação do trabalho de formação inicial dos professores; o segundo, parte de movimento oposto, mas não contrário, ou seja, da necessidade de aproximar a formação inicial dos professores das pesquisas em educação [...]. (SOARES, 2014, p. 445)
\end{abstract}

A afirmação de Soares reitera o necessário vínculo entre as pesquisas acadêmicas e a formação inicial de professores nas licenciaturas, como uma variável que imprime qualidade aos processos formativos. Não é factível que as pesquisas científicas não dialoguem com os processos formativos, e que os mesmos não tenham como uma pauta de ação justamente as pesquisas.

A maioria dos partícipes dos grupos focais relatou desconhecer, ao longo dos seus cursos de licenciatura, investimentos mais densos na área da pesquisa. Um deles chegou a referir que, apesar de realizar sua licenciatura no espaço de uma unidade acadêmica que tinha programa de pós-graduação - e portanto, pesquisas desenvolvidas -, não reconhecia o presença da pesquisa como algo inerente ao seu próprio processo formativo, ficando tal atividade restrita aos 'eleitos', ou aos alunos formados, quando aprovados em processos seletivos próprios.

A tímida presença da pesquisa como elemento formativo - ou vinculada apenas à pósgraduação stricto sensu - foi marcante no relato de $90 \%$ dos 20 sujeitos participantes do grupo focal: 10 sujeitos em um grupo e 08 sujeitos em outro grupo. A questão mais interessante reside na uniformidade das falas e das interações. Mesmo sem se conhecerem, membros dos dois grupos focais fizeram relatos e interações bastante similares sobre o assunto em tela.

Sublinha-se a crença de que a formação ontológica de futuros professores não prescinde seu envolvimento "em comunidades de investigação e/ou redes, buscando, com os outros, construir um conhecimento significativo local, em que a investigação é reconhecida como parte de um esforço maior de transformar o ensino, o aprendizado e a escola" (CRUZ, 2017, p. 1171). A pesquisa é, assim, um ingrediente formativo essencial, e não apenas um componente reservado a níveis posteriores de formação acadêmica.

Em um segundo ponto, a materialidade de situações reais precisa estar presente na formação do professor, seja por meio da pesquisa e/ou por meio do cotidiano de atuação docente como dimensão formativa por excelência. Nessa direção, "seria desejável que o 
campo de trabalho real de profissionais professores fosse referência para sua formação, não como constrição, mas como foco de inspiração concreta" (GATTI, 2014, p. 39).

Os egressos, participantes dos grupos focais, referiram que os espaços reais da sala de aula foram pouco explorados em suas formações iniciais. Relatam muito aprendizado em disciplinas vinculadas às práticas de ensino e aos estágios curriculares supervisionados - como era de se esperar -, porém em outras disciplinas mais propedêuticas, os egressos relataram o sentimento de distância entre a teoria e a sala de aula.

De outro modo, nas decisões estruturais de um currículo, aspectos conjunturais merecem um espaço de relevo, sob pena da formação ficar 'descolada' da realidade material da profissão docente...

Parece não restar dúvida quanto à existência de variáveis e de condições objetivas (de ordem política, econômica, social e cultural) que determinam e muitas vezes se tornam obstáculos ao trabalho do professor. Portanto, sua formação não pode prescindir de situar em que tipo de sociedade e quais problemas os seus membros enfrentam, seja na escola ou fora dela (GIOVINAZZO, 2017, p.55).

Além do mais "o contexto escolar permite refletir a multiplicidade de relações em torno da educação escolar, seja do ponto de vista ideológico, social, econômico, histórico, seja das questões locais inerentes à gestão, à coordenação, às condições físicas e aos ideais circundantes" (DIAS; SOUZA, 2017, p.18). Trata-se da realidade sem simulações, na qual o futuro docente desenvolverá sua prática pedagógica.

Muito em razão da necessidade de diálogo entre a pesquisa e a necessidade de emparelhamento entre a formação e o campo de atuação, há algum tempo as Políticas Educacionais oriundas do executivo têm convergido para a aproximação orgânica entre a Educação Básica e o Ensino Superior, principalmente por meio de políticas de estado, materializadas em legislações, como por meio da Lei $n^{\circ}$ 13.174, de 2015 - que altera a LDB 9.394/1996, incluindo entre as finalidades da educação superior, seu envolvimento com a Educação Básica - e da Portaria n 158, de 10 de agosto de 2017 - que convida a IES a apresentar sua política institucional de formação de professores para a Educação Básica para apresentar candidatura a editais de fomento da Diretoria de Formação de Professores da Educação Básica (DEB) da CAPES.

Há, nessas e em outras políticas atuais, uma clara tendência de ampliação e fortalecimento dos movimentos de aproximação entre a Educação Básica e o Ensino Superior, mormente por meio dos cursos de formação de professores.

\section{CONSIDERAÇÕES}

Avizinha-se o risco de 'apagão' docente na Educação Básica brasileira, consubstanciado em dois contextos quantitativos: a parca opção por cursos de licenciatura, cujas matrículas não chegaram a $20 \%$ do total no ensino superior em 2016; ou pela defasagem quantitativa evidente entre o número de professores jovens (até os 24 anos) e o número de professores com 50 anos ou mais, presumivelmente na etapa final de suas carreiras. 
Para fazer frente ao deficit de professores, as políticas educacionais (de estado e de governo) têm dado conta de soluções imediatas e emergenciais. Acredita-se que, para dar conta efetiva do fenômeno, sejam necessárias soluções estruturais que passariam por dois movimentos: a) o investimento na atratividade e na permanência na carreira docente, e b) o fortalecimento dos cursos de licenciatura como espaço primordial de formação docente inicial. Nessa direção levantaram-se, no decorrer do texto, algumas questões que colaboram na problematização do ensino nos cursos de licenciatura.

Tais questões foram levantadas a partir da técnica do Grupo Focal, aplicada a egressos de cursos de licenciatura de uma universidade do norte do estado do Rio Grande do Sul. Estes grupos focais serviram de espaço para produção de dados, a partir das memórias e das discussões circunstanciadas sobre os processos formativos aos quais os sujeitos foram submetidos ao longo dos seus cursos de licenciatura. Longe da crítica, pois não há estofo quantitativo para tanto, as discussões serviram de base para o levantamento de questões essenciais que carecem um espaço quando do debate acerca da formação docente no âmbito das licenciaturas, especialmente como ação de estímulo ao debate e à ação concreta de combate ao risco iminente de 'apagão' de professores.

Portanto, no que concerne ao debate teórico acerca do ensino nos cursos de licenciatura, há duas perspectivas suscitadas pelos grupos focais: a) a necessidade de cursos específicos para a formação docente, implicando o entendimento relativamente consensual de que a atividade docente não pode ser descolada de uma preparação específica; e b) a convivência curricular de dois grandes núcleos: os conhecimentos disciplinares e os conhecimentos pedagógicos ou didáticos, ambos tomados como elementos centrais na formação de professores.

Além do mais, ainda fica evidente nos grupos focais a necessidade de alinhamento entre as pesquisas na área educacional, o espaço de atuação docente como materialidade e os atuais desenhos de políticas educacionais, o que tem convergido para a aproximação orgânica entre a educação básica e o ensino superior, trazendo a pertinência desse movimento como elemento essencial no currículo das licenciaturas.

\section{REFERÊNCIAS}

BARDIN, L. Análise de Conteúdo. Trad. Luiz Antero Reto e Augusto Pinheiro. Lisboa: Edições 70, 2007.

BRASIL. Conselho Nacional de Educação. Escassez de professores no Ensino Médio: propostas estruturais e emergenciais. Relatório produzido pela Comissão Especial instituída para estudar medidas que visem a superar o déficit docente no Ensino Médio (CNE/CEB), 2007, http://portal.mec. gov.br/cne/arquivos/pdf/escassez1.pdf>.

BRASIL. Ministério da Educação. Censo da Educação Superior 2016 - Notas Estatísticas, 2017. [Publicizado em 31 de agosto de 2017]. Capturado do site: <http://portal.mec.gov.br/index. php?option=com_docman\&view $=$ download\&alias $=71221$-notas-sobre-censo-educacao-superior2016-pdf\&category_slug=agosto-2017-pdf\&Itemid=30192> , em 24 de janeiro de 2018.

BRASIL. Ministério da Educação. Parecer CNE/CP No 2/2015, de 9 de junho de 2015. Diretrizes Curriculares Nacionais para a Formação Inicial e Continuada dos Profissionais do Magistério da Educação Básica. Brasília: Conselho Nacional de Educação - Conselho Pleno, 2015. 
BOMFIM, L. A. Grupos focais: conceitos, procedimentos e reflexões baseadas em experiências com o uso da técnica em pesquisas de saúde. Physis - Revista de Saúde Coletiva, v. 19, n. 3, p. 777-796, 2009

CERICATO, I. L. A profissão docente em análise no Brasil: uma revisão bibliográfica. Revista Brasileira de Estudos Pedagógicos, Brasília, v. 97, n. 246, p. 273-289, ago. 2016.

CRUZ, G. B. da. Ensino de didática e aprendizagem da docência na formação inicial de professores. Cadernos de Pesquisa, São Paulo, v. 47, n. 166, p. 1166-1195, dez. 2017.

DIAS, M. da S.; SOUZA, N. M. M. de. Contribuições para compreender a formação na licenciatura e na docência. Educação em Revista. Belo Horizonte, v. 33, e157758, 2017.

FRIGOTTO, G. Educação profissional e capitalismo dependente: o enigma da falta e sobra de profissionais qualificados. Trabalho, educação e saúde, Rio de Janeiro, v. 5, n. 3, p. 521-536, nov. 2007.

GATTI, B. A. Formação de professores e carreira - Problemas e movimentos de renovação. Campinas, SP: Autores Associados, 1991. (Coleção Formação de Professores).

GATTI, B. A. A formação inicial de professores para a educação básica: as licenciaturas. Revista USP. São Paulo. n. 100. p. 33-46 fev.2014

GIOVINAZZO JUNIOR, C. A. A formação profissional nos cursos de licenciatura e o exercício do magistério na educação básica: intenções, realizações e ambiguidades. Educação em Revista, Curitiba, n. spe.1, p. 51-68, jun. 2017.

LIBÂNEO, J. C. O Campo Teórico-Investigativo e Profissional da Didática e a Formação de professores. Didática e formação de professores: perspectivas e inovações. Goiânia, CEPED, PUC Goiás, 2012.

LOPES, A. C. Conhecimento escolar: ciência e cotidiano. Rio de Janeiro: EdUERJ, 1999.

MASSON, G. Requisitos essenciais para a atratividade e a permanência na carreira docente. Educação \& Sociedade, Campinas, v. 38, n. 140, p. 849-864, jul. 2017.

MONFREDINI, I. et al. O deserto da formação inicial nas licenciaturas e alguns oásis. Jundiaí: Paco Editorial, 2013.

NÓVOA, A. A formação de professores e profissão docente. In: NÓVOA, A. Os professores e a sua formação. Lisboa: Dom Quixote, 1992, p. 17-33.

SOARES, A. S. A formação do professor da Educação Básica entre políticas públicas e pesquisas educacionais: uma experiência no Vale do Jequitinhonha em Minas Gerais. Ensaio: Avaliação e Políticas Púbicas em Educação, Rio de Janeiro, v. 22, n. 83, p. 443-64, abr./jun. 2014.

TARDIF, M. Saberes docentes e formação profissional. 15. ed. Petrópolis, RJ: Vozes, 2013.

Artigo recebido em: 10/04/2018 Aprovado em: 20/06/2018 Contato para correspondência: Rosimar Serena Siqueira Esquinsani. E-mail: rosimaresquinsani@upf.br 